\title{
The Effect of Trimethoprim on Macromolecular Synthesis in Escherichia coli
}

\author{
GENERAL EFFECTS ON RIBONUCLEIC ACID AND PROTEIN SYNTHESIS
}

\author{
By R. J. SMITH and J. E. M. MIDGLEY \\ Department of Biochemistry, University of Newcastle upon Tyne, \\ Newcastle upon Tyne NE1 7RU, U.K.
}

(Received 12 February 1973)

\begin{abstract}
In trimethoprim-inhibited $\mathrm{RC}^{\text {str }}$ strains of Escherichia coli, the expression of the $R C$ control of stable RNA synthesis arose primarily from a decrease in the intracellular concentrations of glycine and methionine, and not from inhibition of the initiation of new protein chains. In non-supplemented cultures, experiments with rifampicin showed that the immediate response to the addition of trimethoprim was a rapid decrease in the rate of initiation of RNA chains. This was followed after a few minutes by a sufficiently large fall in the rate of endogenous synthesis of nucleotide bases to cause a decrease in the rate of RNA chain polymerization. Inhibition of RNA chain initiation was thus overridden by an accumulation of DNA-dependent RNA polymerases upon the cistrons. $R^{\text {rel }}$ strains also accumulated polymerases upon the DNA in similar circumstances, but did not suffer the initial effects on chain initiation. If purines were supplied before adding trimethoprim, $\mathrm{RC}^{\text {str }}$ strains polymerized $\mathrm{RNA}$ chains at normal rates, but initiation rates were permanently decreased. In either situation, an increased \% of the RNA formed was mRNA. However, in $\mathrm{RC}^{\text {rel }}$ strains supplemented with bases, trimethoprim did not affect either the rate of initiation of new chains or their rates of polymerization or the relative rates of synthesis of stable RNA and mRNA. Protein synthesis was also severely inhibited by trimethoprim. Though the addition of glycine and methionine to base-supplemented, trimethoprim-inhibited $\mathrm{RC}^{\text {str }}$ strains did not apparently affect the decreased rate of protein synthesis, RNA accumulation resumed at its normal rate. Thus, the inhibition of protein chain initiation had no effect on the rate of RNA accumulation in either RC $C^{\text {str }}$ or RC Rel bacteria. The $R C$ control does not express itself through inhibitions of protein synthesis at this level.
\end{abstract}

Trimethoprim [2,4-diamino-5(3', $4^{\prime}, 5^{\prime}$-trimethoxybenzyl)pyrimidine] inhibits the bacterial enzyme tetrahydrofolate dehydrogenase (EC 1.5.1.3) (Burchall \& Hitchings, 1965; Hitchings \& Burchall, 1965). As the tetrahydrofolate pool is continuously depleted through the formation of thymidylic acid for DNA synthesis (Bertino \& Stacey, 1966) the cells become deprived of this cofactor. The tetrahydrofolate is essential for the incorporation of $C_{1}$ units into the 5 -methyl moiety of thymine (Huennekens, 1963), in the formation of the amino acids glycine and methionine (Kisliuk \& Sakami, 1954; Guest \& Woods, 1960), and of purines and pyrimidines for general nucleic acid synthesis (Magasanik, 1962) and $N$-formylmethionyl-tRNA ${ }^{\text {fMet }}$ in the initiation of protein chains (Eisenstadt \& Lengyel, 1966). Trimethoprim therefore exerts several inhibitory effects on most of the pathways of macromolecular biosynthesis in bacteria.

In the presence of exogenous purines and pyrimidines, $\mathbf{R C}^{\text {str }}$ strains display the stringent control of RNA and protein synthesis (Shih et al., 1966; Edlin \& Stent, 1969), whereas RC Rel $^{\text {strains }}$ continue to accumulate RNA. However, Moivic \& Pizer (1971) and Dale \& Greenberg (1972) have shown that the imposition of the $\mathrm{RC}^{\text {str }}$ response may arise from a curtailment in the synthesis of some amino acids and not, as suggested by Shih et al. (1966), through a specific inhibition of protein chain initiation. The addition of several amino acids lifts the inhibition of RNA accumulation in RC Cells $^{\text {str }}$ (Dale \& Greenberg, 1972).

At the same time, trimethoprim-inhibited RCstr strains differ from auxotrophs deprived of amino acids, in that the former remain capable of utilizing exogenous nucleotide bases for RNA synthesis (Edlin \& Stent, 1969; Gray et al., 1972). In contrast, RC $^{\text {str }}$ amino acid auxotrophs lose their capacity to take up exogenous bases in the absence of supplied amino acids (Edlin \& Neuhard, 1967), even when a prior base deficiency has also been imposed on the cells (Gray \& Midgley, 1972). 
In this and the following papers (Midgley \& Smith, 1973; Smith \& Midgley, 1973) we describe detailed studies on the effects of trimethoprim on the synthesis of protein, and stable and messenger RNA species in $\mathrm{RC}^{\text {str }}$ and $\mathrm{RC}^{\mathrm{rel}}$ strains of $E$. coli. The relative importance of the events arising from trimethoprim inhibition in preventing the synthesis of macromolecules was assessed. Our results, in agreement with the findings of Angehrn \& Then (1972) and Dale \& Greenberg (1972), show that the RC control of stable RNA formation acts primarily through a lack of glycine and methionine. A preliminary account of this work has been given (Smith, 1972).

\section{Materials and Methods}

The strains of bacteria used were Escherichia coli MRE600 (ribonuclease $\mathrm{I}^{-}, \mathrm{RC}^{\mathrm{str}}$ ), CP78 $\left(\mathrm{F}^{-}\right.$, $\mathrm{Thr}^{-}, \mathrm{Leu}^{-}, \mathrm{His}^{-}, \mathrm{Arg}^{-}, \mathrm{Mal}^{-}, \mathrm{Xyl}^{-}, \mathrm{Ara}^{-}, \mathrm{Gal}^{-}$, $S m^{\text {s }}, R C^{\text {str }}$ ) and CP79 (isogenic with CP78 except $R C^{\text {rel }}$ ).

The strains were grown, with forced aeration, in the media described by Gray \& Midgley (1970) and Gray \& Midgley (1972). The labelling of RNA, harvesting of cultures, extraction of RNA, DNA and ribosomes and the hybridization of $\mathrm{MRNA}$ upon denatured DNA immobilized on membrane filters was carried out as described by Pigott \& Midgley (1968).

Sucrose-density-gradient sedimentation of RNA was done by the method of Avery \& Midgley (1969).

Chloramphenicol was obtained from Sigma Chemical Co., St. Louis, Mo., U.S.A. Rifampicin was a kind gift from Lepetit Pharmaceuticals Ltd., Maidenhead, Berks., U.K. Trimethoprim lactate was a kind gift from Wellcome Research Laboratories, Dartford, Kent, U.K.

$\left[2-{ }^{14} \mathrm{C}\right]$ Uracil (specific radioactivity $54.5 \mathrm{mCi} /$ $\mathrm{mmol}$ ), $\left[5-{ }^{3} \mathrm{H}\right]$ uracil (specific radioactivity $1 \mathrm{Ci} /$ $\mathrm{mmol}$ ) and $\mathrm{DL}-\left[1-{ }^{14} \mathrm{C}\right]$ leucine (specific radioactivity $61 \mathrm{mCi} / \mathrm{mmol}$ ) were obtained from The Radiochemical Centre, Amersham, Bucks., U.K.

\section{Results}

Response of $R C^{s t r}$ and $R C^{r e l}$ strains of $E$. coli to trimethoprim

Shih et al. (1966) showed that the state of the RC gene in $E$. coli mutants governed their response to trimethoprim in the presence of exogenously supplied nucleotide bases. To confirm their findings, E. coli CP78 (RC'str) and CP79 $\left(\mathrm{RC}^{\text {rel }}\right)$ were grown in amino acid-supplemented glucose-salts medium (Gray \& Midgley, 1972) and tested for their ability to synthesize RNA during inhibition by trimethoprim, at a concentration of $50 \mu \mathrm{g} / \mathrm{ml}$.
Whereas the addition of trimethoprim alone, without purine base supplements, gave rise to a rapid inhibition of RNA accumulation in both $\mathbf{R C}^{\text {str }}$ and $\mathbf{R C}^{\mathrm{rel}}$ strains after $5 \mathrm{~min}$, the strains were distinguished by their differing response when purines were also supplied. In supplemented cultures, the $\mathbf{R C}^{\text {str }}$ strain rapidly became unable to form RNA, but the $R^{\text {rel }}$ strain continued to accumulate RNA at the uninhibited rate for some $30 \mathrm{~min}$ after the addition of trimethoprim. In all cases, the labelling of DNA was negligible because of the inhibition of thymidylic acid synthesis (Bertino \& Stacey, 1966). The bacteria thus display the expected RC control function in the appropriate conditions, though the effect of nucleotide base deprivation is, of course, paramount (Shih et al., 1966).

Rate of polymerization of RNA chains in purinesupplemented and unsupplemented $R C^{\text {str }}$ and $R C^{r e l}$ strains inhibited with trimethoprim

The polymerization of nascent RNA chains in bacterial cells can be measured by observing the kinetics of residual RNA labelling after the inhibition of initiation by rifampicin (Pato \& von Meyenberg, 1970). A general assumption made is that the time at which net incorporation of exogenous labelled precursors into RNA ceases is a measure of the time needed to complete the longest chains of stable RNA (Gray \& Midgley, 1971). As the cistron for 16S and 23S (+5S) rRNA synthesis is tandem (Purdom et al., 1970) and has one rifampicin-sensitive initiation point (Pato \& von Meyenberg, 1970; Bremer \& Berry, 1971; Doolittle \& Pace, 1971) the residual labelling of RNA must chiefly involve the transcription of cistrons for rRNA synthesis. As argued by Gray \& Midgley (1972), even when mRNA may predominate in the rapidly labelled RNA fraction from uninhibited bacteria, the probability that the $16 S+23 S+5 S$ rRNA cistron (5000 nucleotide residues) forms a much larger product than the average mRNA molecule will exaggerate the contribution of rRNA labelling in rifampicininhibited cultures.

With this antibiotic, the polymerization rates for RNA chains at $37^{\circ} \mathrm{C}$ were compared in $E$. coli MRE600 (RC str $^{\text {str }}$ CP78 $\left(\mathrm{RC}^{\text {str }}\right)$ and CP79 $\left(\mathrm{RC}^{\text {rel }}\right)$, after inhibition with trimethoprim (see Fig. 1 for details). The trimethoprim inhibition had no effect on the rate of polymerization of RNA chains, as compared with steadily growing controls (Gray \& Midgley, 1971). This, in the case of inhibited RC $C^{\text {str }}$ strains, was accompanied by a gross decrease in the amount of residual RNA labelling. $\mathrm{RC}^{\text {rel }}$ strains were not affected in this way.

Similar experiments were carried out, in which purines were not supplied to the cells before the addition of trimethoprim. This gave rise to a 
deficiency in RNA precursors, so that the decreased contents of these in the cells would presumably dictate the rate of nascent-chain elongation. Fig. 2 shows

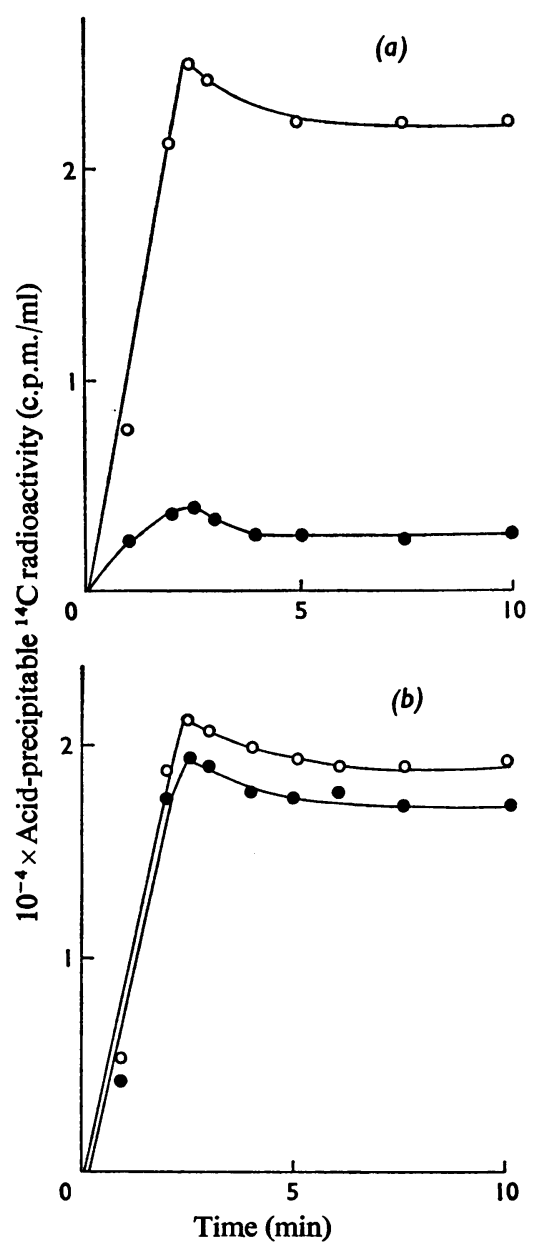

Fig. 1. Residual RNA labelling after the addition of rifampicin to purine-supplemented, drug-inhibited $R C^{\text {str }}$ and $R C^{\text {rel }}$ E. coli

Cultures of E. coli CP78 (RC'str) and CP79 (RC'rel) were grown in glucose-salts media containing required amino acids. At $E_{650}=0.5$, the cultures were supplemented with adenine + guanosine $(50 \mu \mathrm{g} /$ $\mathrm{ml}$ each). After $10 \mathrm{~min}$, trimethoprim $(50 \mu \mathrm{g} / \mathrm{ml})$ was added and inhibition of RNA labelling in $\mathrm{RC}^{\text {str }}$ organisms was completed some $5 \mathrm{~min}$ later. At $10 \mathrm{~min}$ after the onset of trimethoprim inhibition, rifampicin, $(100 \mu \mathrm{g} / \mathrm{ml})$ and $\left[2-{ }^{14} \mathrm{C}\right] u r a c i l$, specific radioactivity $54 \mathrm{mCi} / \mathrm{mmol}$, concentration $0.04 \mu \mathrm{Ci} /$ $\mathrm{ml}$, were added simultaneously. (a) E. coli CP78 (RC'str); (b) E. coli CP79 (RC $\left.\mathrm{R}^{\mathrm{rel}}\right)$; O, growing culture; $\bullet$, trimethoprim-inhibited culture. that this was the case for both the $\mathrm{RC}^{\text {str }}$ and $\mathrm{RC}^{\mathrm{rel}}$ strains. Whereas, if purines were supplied exogenously, it took about $2 \mathrm{~min}$ at $37^{\circ} \mathrm{C}$ to complete residual RNA labelling after rifampicin inhibition (Fig. 1), it took about $20 \mathrm{~min}$ in their absence. This indicates that, if the completion of labelling of the same RNA species signals the end of general RNA labelling in both cases, deprivation of nucleotide bases in trimethoprim-inhibited, unsupplemented cells leads to a tenfold decrease in the rate of RNA chain polymerization.

Distribution of DNA-dependent RNA polymerases on the cistrons of trimethoprim-inhibited cells

The extent of residual labelling of RNA in rifampicin-inhibited cultures is also a rough guide to the active engagement of polymerases in RNA synthesis upon the cistrons. This method of estimation is, however, affected by changes in the concentrations of the nucleotide pools in the cells. In trimethopriminhibited, purine and pyrimidine-supplemented $\mathbf{R C}^{\text {str }}$ strains, the concentrations of intracellular nucleotide precursors of RNA are virtually unchanged from those found in steadily growing cells (Edlin \& Stent, 1969). If pyrimidines are supplied to trimethoprim-inhibited cultures in the absence of purines, the concentrations of the pyrimidine nucleotide pools increase, even though those of the purine nucleotides are especially decreased (J. E. M. Midgley, unpublished work). Analogous effects were seen in the concentrations of purine nucleotides in uracildeprived auxotrophs (Gallant \& Harada, 1969). It is therefore likely that residual labelling by



Fig. 2. Residual RNA labelling after the addition of rifampicin to purine-starved, trimethoprim-inhibited $R C^{\text {str }}$ and $R C^{\text {rel }}$ E.coli

Rifampicin was added as shown by the dashed line.

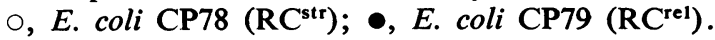


uracil in trimethoprim- and rifampicin-inhibited cultures, and thus estimates of polymerase activity, are somewhat distorted by large alterations in the nucleotide pools that affect the degree of dilution of the labelled base entering newly formed RNA. However, as the pyrimidine nucleotide pools are expanded, increases in the residual labelling of RNA will lead to underestimates of the true increase in enzyme activity.

To study changes in the extent of residual RNA labelling in trimethoprim-inhibited bacteria, cultures were inhibited with trimethoprim and tested, after the addition of rifampicin, for RNA labelling potential with $\left[2-{ }^{14} \mathrm{C}\right]$ uracil (see Fig. 3 for details). In purine-supplemented, trimethoprim-inhibited $\mathrm{RC}^{\text {str }}$ cells, the residual labelling of RNA after the addition of rifampicin fell quickly by a factor of ten, and remained at this or lower values throughout further incubation. In $\mathrm{RC}^{\text {rel }}$ cells, this fall was absent. In unsupplemented, trimethoprim-inhibited $\mathrm{RC}^{\text {str }}$ cultures, the residual RNA labelling was at first decreased, over a period of some $5-10 \mathrm{~min}$ after the addition of trimethoprim, but then steadily rose to a final value some 2.5 times that typical of growing cells. In $\mathrm{RC}^{\text {rel }}$ cultures, the initial decrease in labelling capacity was almost absent in each case, though when purines were omitted, residual RNA labelling rose by a factor of two over that found in steadily growing controls.

It would appear that when $\mathbf{R C}^{\text {str }}$ cultures were also supplemented with purines, there was a large decrease in the number of DNA-dependent RNA polymerase molecules active in transcription. Alternatively, it could be argued that, when the bases were added, the cells shortly afterwards became unable to utilize them efficiently in RNA synthesis, because of the onset of the restrictive phenomenon noted during simple amino acid deprivation of $\mathbf{R C}^{\text {str }}$ auxotrophs (Edlin \& Neuhard, 1967). To answer this point, comparisons were made between the rate of RNA labelling before and after the addition of trimethoprim + bases in randomly labelled and in rapidly labelled cultures. In one experiment, $\left[5-{ }^{3} \mathrm{H}\right]-$ uracil was added to growing cultures of $E$. coli MRE600, and the cells were allowed to divide for four generations with a steady uptake of radioactive isotope. At a suitable time, the culture was split into two, and to one part, trimethoprim $(50 \mu \mathrm{g} / \mathrm{ml})$ and adenine + guanosine $(50 \mu \mathrm{g} / \mathrm{ml})$ were added. To the other were added the bases alone. Labelling



Fig. 3. Changes in the extent of residual RNA labelling during trimethoprim inhibition of $R C^{\text {str }}$ or $R C^{\text {rel }} E$. coli after the addition of rifampicin

(a) Purine-supplemented strain CP78 (RC $\left.C^{\text {str }}\right)$; (b) purine-supplemented strain CP79 $\left(\mathrm{RC}^{\mathrm{rel}}\right)$; (c) non-supplemented strain CP78 ( $\left.\mathrm{RC}^{\text {str }}\right) ;(d)$ non-supplemented strain $\mathrm{CP} 79\left(\mathrm{RC}^{\mathrm{rel}}\right)$. Cultures growing in supplemented glucose-salts media were divided into two parts. To one adenine and guanosine were added $(50 \mu \mathrm{g} / \mathrm{ml} \mathrm{final} \mathrm{concentration),}$ followed after $5 \mathrm{~min}$ by trimethoprim $(50 \mu \mathrm{g} / \mathrm{ml})$. Samples $(10 \mathrm{ml})$ were removed from the inhibited cultures and RNA chain initiation was stopped by rifampicin $(100 \mu \mathrm{g} / \mathrm{ml})$. $\left[2-{ }^{14} \mathrm{C}\right]$ Uracil (specific radioactivity $54 \mathrm{mCi} / \mathrm{mmol}$, $0.1 \mu \mathrm{Ci} / \mathrm{ml}$ ) was added simultaneously, and residual RNA labelling was measured by rapid sampling and precipitation with trichloroacetic acid. To the other part, no adenine or guanosine was added at first. Measurement of residual RNA labelling in the rifampicin-inhibited cells was made as before, except that the purines $(50 \mu \mathrm{g} / \mathrm{ml}$ each) were added with the antibiotic to relieve the deficiency. The cellular potential for RNA labelling was measured for each culture at the following times during trimethoprim inhibition: $0 \mathrm{~min}, \circ ; 2 \mathrm{~min}, \Delta ; 5 \mathrm{~min}, \bullet$; $10 \mathrm{~min}, \triangle ; 20 \mathrm{~min}, \odot ; 30 \mathrm{~min}, \odot ; 40 \mathrm{~min}, \odot ; 60 \mathrm{~min}, \odot$. Preincubation of cultures with unlabelled pyrimidines did not affect the observed changes in RNA labelling patterns. 
was continued and monitored by acid precipitation. In another experiment, labelling was not commenced until $5 \mathrm{~min}$ after the addition of trimethoprim + bases, and the rate of labelling in the inhibited culture was compared with that of the growing control. In a third experiment, the accumulation of RNA in inhibited and growing cultures was measured by the colorimetric assay of Schneider (1957). The results are shown in Table 1. There is little difference between the ratios of RNA labelling rates in inhibited cultures/ labelling rates in growing controls in either case, and both are in close agreement with the ratio of the rates of RNA accumulation in inhibited cultures/ those in growing cultures. This indicates that the trimethoprim-inhibited cultures do not suffer greatly from an inability to utilize exogenous bases from the medium in the formation of RNA.

The effect of trimethoprim inhibition on RNA synthesis in cultures not given purine supplements is, in its final result, analogous to the deprivation of purine-requiring auxotrophs of $E$. coli (Thomas et al., 1970; Varney et al., 1970). At first, the DNAdependent RNA polymerase molecules appeared to run off the cistrons, since residual RNA labelling after addition of rifampicin declined during the first $5 \mathrm{~min}$ of trimethoprim inhibition. In this period, the rate of polymerization of RNA chains was not affected. Later, the decrease in the rate of chain polymerization caused a steady accumulation of enzymes upon the cistrons, until the potential for residual RNA labelling after the addition of rifampicin was about twice that found in steadily growing cells. This indicates that the polymerases known to be in excess of the steady state requirements for RNA synthesis in these conditions (Maaløe \& Kjeldgaard, 1966; Midgley \& Gray, 1971) are now actively engaged in transcription. This suggests that the decrease in the rate of polymerization of RNA

Table 1. Synthesis of RNA in growing and trimethoprim-inhibited E. coli MRE600

All measurements are the mean of estimations (each in triplicate) made on three cultures.

Culture conditions

Steady growth

Trimethoprim-inhibited

Steady growth

Trimethoprim-inhibited

0min, growing

$60 \mathrm{~min}$, growing

$60 \mathrm{~min}$, trimethoprim-inhibited
Rate of RNA labelling (\%)

100

$8 \pm 2$

100

$5 \pm 2$
Method of analysis

Random labelling with $\left[{ }^{3} \mathrm{H}\right]$ uracil

Pulse labelling with $\left[{ }^{3} \mathrm{H}\right]$ uracil

Amount of RNA (\%)

100

$215 \pm 10$

$112 \pm 5$
Orcinol colorimetric estimation


Fig. 4. Sucrose-density-gradient sedimentation of rapidly labelled RNA in growing and trimethoprim-inhibited E. coli MRE600 (RC str $)$

(a) Growing culture, $2 \mathrm{~min}$ label; (b) purine-supplemented, trimethoprim-inhibited culture, $2 \mathrm{~min}$ label. $\bigcirc, E_{260}$; $\bullet,{ }^{3} \mathrm{H}$ c.p.m. Both growing and trimethoprim-inhibited E. coli $\mathrm{CP} 79\left(\mathrm{RC}^{\mathrm{rel}}\right)$ gave RNA sedimentation patterns similar to that in Fig. 4(a) (J. E. M. Midgley, unpublished work). 
chains caused by a lack of purines has become sufficiently severe to override the earlier decrease in the rate of chain initiation.

When $\mathrm{RC}^{\mathrm{rel}}$ strains were inhibited with trimethoprim and supplemented with purines, the residual labelling of RNA after rifampicin inhibition was unchanged from the values typical of normally growing cultures. Thus, in $\mathrm{RC}^{\mathrm{rel}}$ strains, no constraints are placed upon the rate of attachment of polymerases to the various cistrons when trimethoprim is added. Later work shows that in $\mathrm{RC}^{\mathrm{rel}}$ mutants there are no significant alterations in the relative fluxes of nucleotide precursors entering mRNA and stable RNA in the presence of trimethoprim and purines.
Synthesis of $m R N A$ and stable RNA during trimethoprim inhibition of $R C^{\text {str }}$ and $R C^{\text {rel }}$ cultures

In Fig. 1, the kinetics of residual RNA labelling after rifampicin inhibition of trimethoprim-inhibited cultures indicated that a considerable proportion of the labelled RNA was stable. To test this finding, cultures of E. coli MRE600 (RC ${ }^{\text {str }}$ ) and CP79 $\left(R^{\text {rel }}\right)$ were supplemented with nucleotide bases and then inhibited with trimethoprim. After $10 \mathrm{~min}$ of inhibition, the cultures were given $\left[5-{ }^{3} \mathrm{H}\right]$ uracil, specific radioactivity $0.1 \mathrm{Ci} / \mathrm{mmol}$, and samples $(100 \mathrm{ml})$ were poured into crushed ice at intervals. RNA was extracted from the samples and subjected to sedimentation through a linear sucrose gradient. The results are shown in Fig. 4.

Table 2. $m R N A$ synthesis in normally growing and trimethoprim-inhibited $R C^{\text {str }}$ and $R C^{\text {rel }}$ strains of $E$. coli

Details of corrections for estimations of mRNA by hybridization are given in Pigott \& Midgley (1968).

Conditions of incubation

(a) $\mathrm{RC}^{\text {atr }}$ cultures

Steadily growing

Trimethoprim-inhibited, supplemented with adenine + guanosine

Trimethoprim-inhibited, non-supplemented

(b) $\mathrm{RC}^{\text {rel }}$ cultures

Steadily growing

Trimethoprim-inhibited, supplemented with adenine + guanosine

Trimethoprim-inhibited, non-supplemented
Time of labelling

(min)

$\begin{array}{rr}0.5 & 34 \\ 2 & 36 \\ 0.5 & 54 \\ 2 & 57 \\ 5 & 40 \\ 15 & 41 \\ 30 & 43 \\ 0.5 & 41 \\ 2 & 55 \\ 5 & 54 \\ 15 & 43 \\ 30 & 43\end{array}$

$0.5 \quad 31$

233

$7 \quad 16$

$16-11$

$30 \quad 5$

$0.5 \quad 36$

2

$7 \quad 25$

16222

$30 \quad 23$

$0.5 \quad 45$

$2 \quad 45$

$7 \quad 48$

$16 \quad 40$

$30 \quad 34$ 
They demonstrate that, compared with the profiles for rapidly labelled RNA from growing cultures, the labelled RNA from trimethoprim-inhibited cells given $\left[5-{ }^{3} \mathrm{H}\right]$ uracil for the same time contained more material with a molecular weight smaller than that of $16 \mathrm{~S}$ rRNA. This is very similar to the corresponding results for $\mathrm{RC}^{\text {str }}$ cells deprived of essential amino acids (Lazzarini \& Dahlberg, 1971; Gray \& Midgley, 1972), where much less labelled material was formed with a sedimentation profile like that of rRNA.

The relative rates of labelling mRNA and stable RNAs in trimethoprim-inhibited cultures was also measured by DNA-RNA hybridization. Hybridization of rapidly ${ }^{3} \mathrm{H}$-labelled RNA from inhibited cultures was carried out at DNA/RNA ratios (w/w) of 5:1 as described by Pigott \& Midgley (1968). The results for purine-supplemented and nonsupplemented cultures are shown in Table 2. Compared with a growing control, the proportion of ${ }^{3} \mathrm{H}$ labelled RNA readily hybridized with the DNA rose from about $35 \%$ to nearly $60 \%$ in $\mathrm{RC}^{\text {str }}$ cultures, but only rose to the higher value in $\mathrm{RC}^{\text {rel }}$ cultures if purines were omitted. These results are in agreement with those taken from an examination of sucrosedensity-gradient profiles of rapidly ${ }^{3} \mathrm{H}$-labelled RNA,

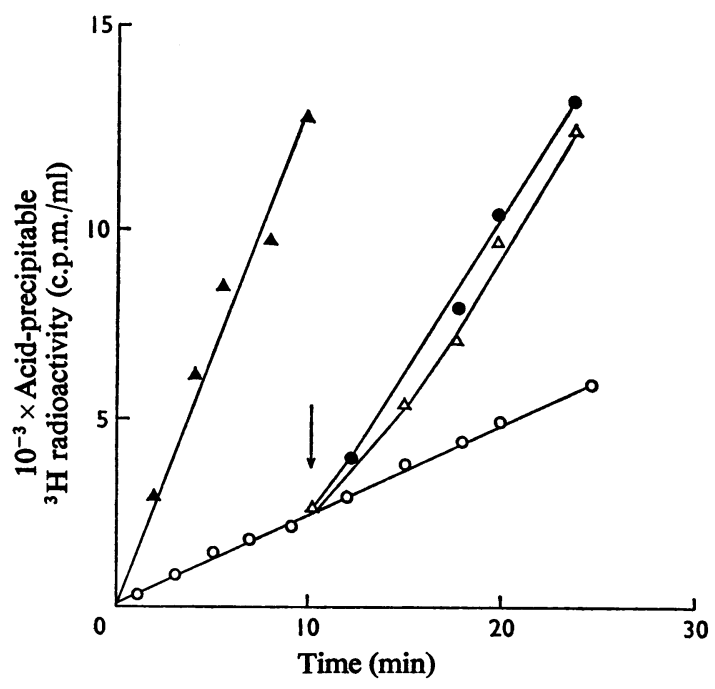

Fig. 5. Effect of amino acids on RNA synthesis in trimethoprim-inhibited $R C^{\text {str }}$ strains of $E$. coli

Labelling of RNA was measured in: $\Delta$, growing control; $O$, trimethoprim-inhibited culture, supplemented with adenine + guanosine + glycine or methionine +18 other amino acids; $\bullet$, trimethopriminhibited culture supplemented with purines + glycine + methionine; $\Delta$, trimethoprim-inhibited culture + purines+chloramphenicol. The arrow indicates the time of addition of the supplements. and the kinetics of residual RNA labelling after rifampicin inhibition. They suggest that in trimethoprim-inhibited $\mathrm{RC}^{\text {str }}$ strains, there is a higher relative flux of labelled uracil into mRNA in trimethoprim-inhibited, as compared with growing, cultures.

$R N A$ accumulation in $R C^{\text {str }}$ strains inhibited with trimethoprim and supplemented with amino acids

In agreement with Shih et al. (1966), trimethoprim quickly prevented the accumulation of RNA in RC ${ }^{\text {atr }}$ cultures supplemented with nucleotide bases, whereas in $\mathrm{RC}^{\text {rel }}$ strains, no such inhibition occurred. If similar experiments were carried out in which, in addition to nucleotide bases, the amino acids glycine and $\mathrm{L}$-methionine were added to $\mathrm{a}$ final concentration of greater than $10 \mu \mathrm{M}$, the accumulation of RNA in $R^{\text {str }}$ cultures quickly resumed (Fig. 5). A similar phenomenon was noted on the addition of chloramphenicol $(0.1 \mathrm{mg} / \mathrm{ml})$ (Shih et al., 1966), or other antibiotics such as puromycin, lincomycin, pactamycin, tetracyclines or erythromycin (J. E. M. Midgley, unpublished work). The antibiotics probably relieved the deficiencies in glycine and methionine by completely preventing protein synthesis, so that protein turnover could refill the depleted amino acid pools. In agreement with this interpretation, preincubation of $\mathbf{R C}^{\text {str }}$ cultures with the above antibiotics for a period of $20 \mathrm{~min}$

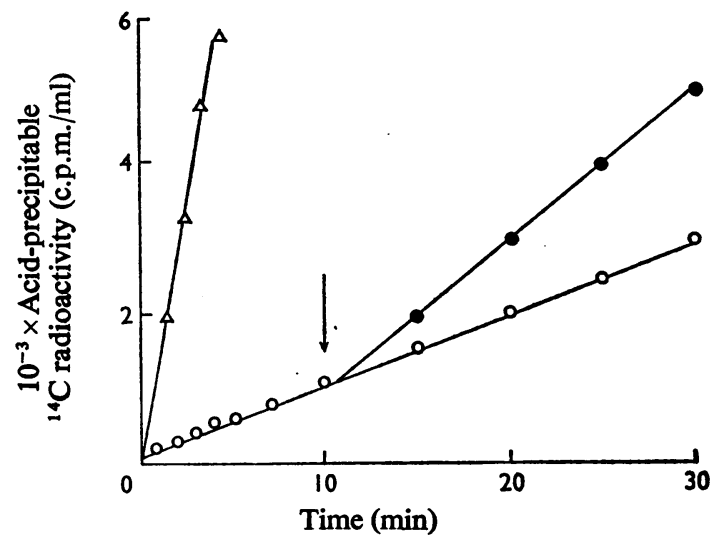

Fig. 6. Labelling of protein in the trimethopriminhibited $R C^{\text {str }}$ strain of $E$. coli

Cultures labelled with $\left[{ }^{14} \mathrm{C}\right]$ leucine are: $\Delta$, growing control; $O$, supplemented with purines and pyrimidines and inhibited with trimethoprim; $\bullet$, inhibited cultures given, in addition, glycine and methionine (arrow). Strain CP79 (RC $\mathrm{RC}^{\mathrm{rel}}$ ) gave the same results as those depicted for the $\mathrm{RC}^{\text {str }}$ strain. 
prevented the immediate inhibition of RNA accumulation when trimethoprim + nucleotide bases were added later (J. E. M. Midgley \& M. Bell, unpublished work). It thus appears that a primary reason for the lack of RNA accumulation in $R^{\text {str }}$ cultures given purines and trimethoprim is a deficiency in amino acids. The results in Fig. 5 show that only glycine and methionine were in sufficiently short supply to cause the inhibition in RNA synthesis, as no recovery was noted when the 18 other common amino acids + either glycine or methionine were added.

On the other hand, the addition of glycine and methionine had little effect on the rate of incorporation of $\mathrm{L}-\left[{ }^{14} \mathrm{C}\right]$ leucine into protein in trimethoprim-inhibited, base-supplemented $R^{\text {str }}$ or $R^{\text {rel }}$ cultures. At most (Fig. 6) the rate of $\left[{ }^{14} \mathrm{C}\right]$ leucine incorporation into protein rose by about $80 \%$ when the two amino acids were added. This suggests that there is still a considerable inhibition imposed at the

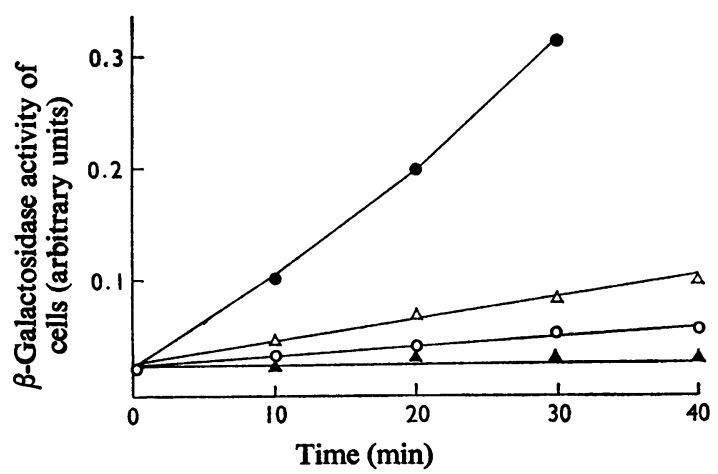

Fig. 7. Induction of $\beta$-galactosidase in trimethopriminhibited $R C^{\text {str }}$ strains of $E$. coli

At $E_{650}=0.4$, a culture of $E$. coli CP78 was split into $3 \times 80 \mathrm{ml}$ portions. To one part, nothing was added at first, but to both the others were added adenine, guanosine, uracil and cytosine $(30 \mu \mathrm{g} / \mathrm{ml}$ each), and trimethoprim $(50 \mu \mathrm{g} / \mathrm{ml})$. After $15 \mathrm{~min}$ of incubation at $37^{\circ} \mathrm{C}$, one of the trimethopriminhibited cultures was given glycine+methionine $(50 \mu \mathrm{g} / \mathrm{ml}$ each). After a further $5 \mathrm{~min}, 30 \mathrm{ml}$ portions were removed from each sample, and $0.5 \mathrm{ml}$ of $0.04 \mathrm{M}$-isopropyl- $\beta$-D-thiogalactopyranoside was added to induce the enzyme. Incubation was continued, and after $10,20,30$ and $40 \mathrm{~min}, 3 \mathrm{ml}$ portions were taken from each of the cultures and $\beta$ galactosidase was assayed, as described by Gray \& Midgley (1971). •, Growing control; $\Delta$, trimethoprim-inhibited culture supplemented with purines + pyrimidines + glycine + methionine; $O$, trimethoprim-inhibited cultures with nucleotide bases only; $\Delta$, non-induced culture. level of protein chain initiation, which cannot be relieved by the addition of amino acids whose intracellular concentrations have also been affected adversely by trimethoprim.

\section{Induction of $\beta$-galactosidase in trimethoprim-inhibited cultures}

Though trimethoprim-inhibited $\mathbf{R C}^{\text {str }}$ and $\mathbf{R C}^{\text {rel }}$ cultures incorporated ${ }^{14} \mathrm{C}$-labelled amino acids into protein at only $5-10 \%$ of the rate in a growing control (Fig. 6), it was possible that this estimation was considerably in error as a true measure of the gross rate of protein synthesis. For example, if the rate of protein synthesis in the cells was close to the rate of degradation by turnover, then exogenous labelled amino acids would be diluted by endogenous breakdown products.

To test these findings, the ability of trimethopriminhibited cells to induce the enzyme $\beta$-galactosidase was compared with the inducing capacity of growing cells.

E. coli $\mathrm{CP78}$ ( $\left.\mathrm{RC}^{\mathrm{str}}\right)$ was grown in amino acidsupplemented lactate-salts medium suitable for the induction of $\beta$-galactosidase (Gray \& Midgley, 1971). It was then inhibited with trimethoprim, and tested for enzyme induction in the presence or absence of added glycine and methionine (see Fig. 7 for details). In this Figure, the curve for enzyme induction in the growing control was normalized to account for the greater concentration of organisms present during induction. Taking the rate of $\beta$-galactosidase



Fig. 8. Induction of $\beta$-galactosidase in trimethopriminhibited $R C^{\text {rel }}$ strains of $E$. coli

-, Growing control; $\Delta$, trimethoprim-inhibited culture supplemented with purines + pyrimidines + glycine + methionine; $\bigcirc$, trimethoprim-inhibited culture with nucleotide bases only; $\Delta$, non-induced culture. 
formation in the growing control as $100 \%$, trimethoprim-inhibited $\mathbf{R C}^{\text {str }}$ organisms were capable of inducing the enzyme at $10 \%$, and glycine +methionine-supplemented organisms at $18 \%$ of the control rate. These values agree well with the finding that glycine + methionine stimulate overall protein labelling in trimethoprim-inhibited cells by about a factor of two.

A similar experiment was carried out for strain CP79 $\left(\mathrm{RC}^{\mathrm{rel}}\right)$. Fig. 8 shows that in this case, trimethoprim-inhibited cultures induced the enzyme at a rate only about $2 \%$ of the growing control, but the addition of glycine and methionine raised this tenfold. Thus, in either $\mathrm{RC}^{\text {str }}$ or $\mathrm{RC}^{\text {rel }}$ strains, the addition of the two amino acids lifted the rate of induction of $\beta$-galactosidase, though in the $\mathrm{RC}^{\text {rel }}$ cultures enzyme activity was increased tenfold, even though the rate of protein labelling overall was only doubled. This discrepancy is probably explained by the fact that, in amino acid-deprived $\mathrm{RC}^{\text {rel }}$ strains, the process of protein chain elongation is inaccurate and results in the formation of enzymically inactive protein (Hall \& Gallant, 1971).

\section{Discussion}

As the action of trimethoprim on bacterial cell growth leads to a deficiency in tetrahydrofolate (Burchall \& Hitchings, 1965; Hitchings \& Burchall, 1965), the implications for macromolecular biosynthesis are that many precursors required for the formation of DNA, RNA and protein will be in short supply. Thus, although a defined supplementation of the growth medium may relieve one rate-limiting step in the biosynthesis of some macromolecules, the far-reaching consequences of tetrahydrofolate lack will almost certainly ensure that another deficiency, in turn, becomes important in inhibiting growth. A study of the relative importance of various systems inhibited by trimethoprim therefore requires considerable care in the interpretation of results.

In the present paper, we have reconsidered the effects of trimethoprim on bacterial macromolecular synthesis, with a view to re-examining the possible relationship between the $\mathrm{RC}$ function in the control of RNA synthesis and the initiation of protein chains (Shih et al., 1966). Our findings suggest that a very early response of bacterial cells to trimethoprim is through a deficiency in the amino acids glycine and methionine, rather than through a lack of $N$-formylmethionyl tRNA ${ }^{\text {fMet }}$ (Eisenstadt \& Lengyel, 1966; Shih et al., 1966; Lengyel, 1967). Thus, the expression of the RC function appears to be related directly to amino acid lack, and the inhibition of stable RNA accumulation in trimethoprim-inhibited $R^{\text {str }}$ cells cannot be implicated with a deficiency in protein initiation factors.
When $\mathrm{RC}^{\text {str }}$ strains of $E$. coli are inhibited with trimethoprim, in the presence of added nucleotide bases, the cells very rapidly lose their ability to accumulate stable RNA at the normal high rate. The phenomenon probably arises from a preferential inhibition of the initiation of stable RNA chains, as the rate of polymerization of nascent RNA chains is unaltered and the proportion of mRNA in the rapidly labelled fraction is increased. On the other hand, $\mathrm{RC}^{\text {rel }}$ strains of $E$. coli continue to accumulate stable RNA at high rates during trimethoprim-inhibition of basesupplemented cultures, though protein synthesis is inhibited. The rRNA is not matured into ribosomes in these conditions (Midgley \& Smith, 1973), a fault that is typical of amino acid-starved $R^{\text {rel }}$ cells (Turnock \& Wild, 1965).

Conclusive evidence that amino acid lack occurs in trimethoprim-inhibited bacteria, and is primarily governing the RC control of RNA accumulation, comes from the finding that addition of glycine and methionine + nucleotide bases to trimethopriminhibited RC $^{\text {str }}$ cells lifts the inhibition on stable RNA accumulation without greatly affecting the inhibition of protein synthesis. In such conditions, trimethoprim-inhibited $\mathbf{R} \mathbf{C}^{\text {str }}$ cultures accumulate stable RNA at a rate close to that found in growing controls, but produce protein at less than $20 \%$ of the normal rate. This suggests that three main deficiencies for protein synthesis in trimethoprim-inhibited cultures have arisen, of which lack of glycine and methionine are more important. When these amino acids are supplied exogenously, protein synthesis rates increase only slightly, as presumably the lesser deficiency in the formation of $\mathrm{N}$-formylmethionyl-tRNA ${ }^{\text {fMet }}$ for protein chain initiation (Lengyel, 1967) now dictates the rate of synthesis overall. The fact that stable RNA accumulates in $\mathbf{R C}^{\text {str }}$ and $\mathrm{RC}^{\text {rel }}$ cells in these conditions shows that the RC function is probably not concerned with defects in the process of protein chain initiation.

R. J.S. thanks the Medical Research Council for a grant for postgraduate studies. We thank Professor K. Burton for valuable discussions and Mrs. M. Bell for her skilled technical assistance.

\section{References}

Angehrn, P. \& Then, R. (1972) Biochim. Biophys. Acta 287, 98-105

Avery, R. J. \& Midgley, J. E. M. (1969) Biochem. J. 115, 383-394

Bertino, J. B. \& Stacey, K. A. (1966) Biochem. J. 101, 32C-33C

Bremer, H. \& Berry, L. (1971) Nature (London) New Biol. 234, 81-83

Burchall, J. J. \& Hitchings, G. H. (1965) Mol. Pharmacol. 1, 126-136

Dale, B. A. \& Greenberg, G. R. (1972) J. Bacteriol. 110, 905-916 
Doolittle, W. F. \& Pace, N. R. (1971) Proc. Nat. Acad. Sci. U.S. 68, 1786-1790

Edlin, G. \& Neuhard, J. (1967) J. Mol. Biol. 24, 225230

Edlin, G. \& Stent, G. S. (1969) Proc. Nat. Acad. Sci. U.S. $62,475-482$

Eisenstadt, J. \& Lengyel, P. (1966) Science 154, 524-527

Gallant, J. \& Harada, B. (1969) J. Biol. Chem. 244, 3125-3132

Gray, W. J. H. \& Midgley, J. E. M. (1970) Biochem. J. 120, 279-288

Gray, W. J. H. \& Midgley, J. E. M. (1971) Biochem. J. 122, 161-169

Gray, W. J. H. \& Midgley, J. E. M. (1972) Biochem. J. 128, 1007-1020

Gray, W. J. H., Vickers, T. G. \& Midgley, J. E. M. (1972) Biochem. J. 128, 1021-1031

Guest, J. R. \& Woods, D. D. (1960) Biochem. J. 77, 422-430

Hall, B. \& Gallant, J. (1971) J. Mol. Biol. 61, 271-273

Hitchings, G. H. \& Burchall, J. J. (1965) Advan. Enzymol. 27, 417-468

Huennekens, F. M. (1963) Biochemistry 2, 151-159

Kisliuk, R. L. \& Sakami, W. (1954) J. Amer. Chem. Soc. 76, 1456-1457

Lazzarini, R. A. \& Dahlberg, A. E. (1971) J. Biol. Chem. 246, 420-429

Lengyel, P. (1967) in Molecular Genetics (Taylor, J. H., ed.), part 2, pp. 193-199, Academic Press, New York
Maaløe, O. \& Kjeldgaard, N. O. (1966) Control of Macromolecular Biosynthesis, p. 97, W. A. Benjamin, New York

Magasanik, B. (1962) in The Bacteria (Gunsalus, I. C. \& Stanier, R. Y., eds.), vol. 3, pp. 295-334, Academic Press, New York

Midgley, J. E. M. \& Gray, W. J. H. (1971) Biochem. J. 122, 149-159

Midgley, J. E. M. \& Smith, R. J. (1973) Biochem. J. 136, 235-247

Moivic, M. \& Pizer, L. I. (1971) J. Bacteriol. 106, 856-862

Pato, M. L. \& von Meyenberg, K. (1970) Cold Spring Harbor Symp. Quant. Biol., 35, 497-504

Pigott, G. H. \& Midgley, J. E. M. (1968) Biochem. J. 110, 251-263

Purdom, I., Bishop, J. O. \& Birnstiel, M. L. (1970) Nature (London) 227, 239-242

Schneider, W. C. (1957) Methods Enzymol. 3, 680-684

Shih, A.-Y., Eisenstadt, J. \& Lengyel, P. (1966) Proc. Nat. Acad. Sci. U.S. 56, 1599-1605

Smith, R. J. (1972) Biochem. J., 129, 38P-39P

Smith, R. J. \& Midgley, J. E. M. (1973) Biochem. J. 136, 249-257

Thomas, G. A., Varney, N. F. \& Burton, K. (1970) Biochem. J. 120, 117-124

Turnock, G. \& Wild, D. G. (1965) Biochem. J. 95, 597607

Varney, N. F., Thomas, G. A. \& Burton, K. (1970) Biochem. J. 120, 125-132 